\title{
Lexical and Grammatical Problems Coped with Communication Strategies
}

\author{
Risa Triassanti \\ Mansur \\ Agus Wardhono \\ Universitas PGRI Ronggolawe Tuban \\ triassantirisa@gmail.com
}

Received: July 30, 2018

Accepted: August 17, 2018

Published: August 31,

\begin{abstract}
Based on preliminary observation most students feel hesitate to continue English conversation when they lacked of vocabularies and structured grammatical sentences. The students prefer to stop speaking. Therefore they need strategies to keep the communication on. Dealing with the problems, the present study investigates the lexical and grammatical communication problems that can be managed by communication strategies. An observation was done to 60 students in different levels of proficiency. it was revealed that there was a significant difference in the frequency and percentage of learners' solved lexical problems $(72.2 \%)$ and grammatical problems $(27.8 \%)$. The results drawn from these items were that EFL students used communication strategies on lexical problems are more frequent than used communication strategies on grammatical problems. This strategy is one small step towards clarifying the balanced of using communication strategy on lexical and grammatical problems in communication.
\end{abstract}

Keywords: lexical, grammatical, communication strategy.

\section{Introduction}

Being able to communicate effectively is the final goal of all EFL teaching. In real communication, learners may encounter lexical, syntactical and phonological problem-3w in both speaking and writing. These problems sometimes made learners stuck in the conversation and remain silent. One approach to solve these problems is developing EFL strategic competence. These strategies keep learners flexible, and confident, and make their communication more effective. Bachman (1990: 124) proposes that communication strategy is a separate part of communicative competence. This element serves function to negotiate meaning in appropriate situation. Therefore, communication strategy is an integrated part in achieving communicative competence. Communication strategies are used to compensate for some deficiency in the linguistic system and focus exploring alternate ways of using what one does know for the transmission of a message without considering situational appropriateness (Tarone, 1981: 287).

Developing communication strategies in EFL class has some important benefits. A significant proportion of real life in L2 proportion is problematic and yet language classes do not generally prepare students to cope with performance problems. One educational approach learners might potentially benefit from in developing their coping skill could be direct teaching of communication strategies. It provide learners with a sense of security in the L2 by allowing them room to plan in times of difficulty rather than giving up their message, learners may decide to try and remain in the conversation and achieve their communicative goal. Providing learners help towards accomplishing this is a worthy objective of communicative language instruction (Dörnyei, 1995).

Communication Strategies, as one of the factors which affect Interlanguage development, have been investigated by researchers since the notion of CS was offered in 1972 by Selinker. Brown (1987) believes communication strategies are one of the sources of errors. The modern view about error is that error is no longer considered as "unwanted forms" but as an evidence of the learner's active contribution on SLA (Ellis, 1985: 54). Therefore, communication strategies have some indirect contributions to SLA and play a constitutive role in second language learning. By allowing learners to remain in conversation, communication strategies help them, on the productive side, to get some useful feedback on their own performance, and on the receptive side, to 
exercise some kind of control over their intake, for example, by enabling them to prompt their interlocutor to modify his or her utterances. In other words, strategic competence promotes learners' self-monitoring function or executive control.

In the context of Lingua Franca English (LFE), a language that bridge communication among nonnative English speakers that use their own English varieties, language errors do not contribute to communication breakdown. An error occurs when someone fails to ascribe meaning to a linguistic form used by another. In LFE, such cases rarely occur. Breakdown in LFE communication is possible only in rare cases of refusal to negotiate meanings - which is itself a form of communication as it conveys the participant's desire to cut off the conversation. Therefore, if there is a case of failed communication, we cannot blame an individual for lack of proficiency. This failed communication might be a divergence strategy (Giles, 1984). Those individuals who assess proficiency have to take into account such joint activity of participants in communication before rushing to rule something a mistake.

Communication strategies is also an important aspect in English as Lingua Franca context. In LFE communication meaning does not precede the language in which it is communicated. In order to express their meaning speakers must continuously work out a joint basis for their interactions, locally interpreting and intersubjectively approving meanings (House, 2003: 559). Therefore, even an ungrammatical usage or inappropriate word choice can be socially functional. They can create a new meaning originally unintended by the speaker, or they may be negotiated by the participants and given new meanings. In a speech community learners have to be trained to shuttle between communities by negotiating the relevant codes. We have to focus more on communicative strategies, rather than on forms of communication. Leaners would develop language awareness (to cope with the multiple languages and emergent grammars of contact situations), rather than focusing only on mastering the grammar rules of a single variety (Canagarajah, 2007: 106)

Some researchers worried about the overuse of communication strategies. Though this capability is necessary in communication, it involves a certain danger: the loss of motivation for further learning and further linguistic development. Many learners may often feel disinclined to invest more efforts in further learning when they know that, after all, they can already cope with the most urgent communication problems. Ellis (2004: 87) also notes that successful use of communication strategies may restrain L2 acquisition. Some learners use the communication strategies so successfully that they do not think it is necessary to form a hypothesis about a particular new target language term and test the hypothesis. More seriously, the language term the learners have used repeatedly to replace the target language term in communication may be "fossilized" and difficult to develop the term into a target language term. On the other hand, if the learner makes efforts to pursue and learn the target language term after successful communication thanks to the use of substitution, paraphrase, restructuring and other achievement strategies, he/she will expand the interlanguage system. Therefore, the role of communication strategies in interlanguage development seems to depend on whether a learner continues his/her efforts to pursue the target term and increase his/her interlanguage repertoire or not after his or her successful communication.

English students (or English major students) in Indonesia are considered a large group who are studying English and need to use CSs to facilitate their communication because they do not have enough exposure to English in daily life. Therefore, they may have formed their own interlanguage system that can provide them with various CSs in English interactions. Empirical investigations that analyse the use of CSs by Indonesian EFL learners are of particular importance. Closely related to the empirical work on second language acquisition (SLA), the study of CSs has achieved success in Asian countries. Recent researches on communication strategies are focusing on some topics such as dominant types of strategy used by EFL learners (Azar \& Mohammadzadeh,2013, Dong \& Peng, 2010, Ting, S.H. \& Lau, L.Y, 2008) relationship between the use of CSs and variables such as proficiency, task type and academic major. They examines not only CSs themselves, but also the variables that mitigate the use of CSs. (Ismail \& Kaur, 2012, Mei,An \& Nathalang, 2010) and the teaching of communication strategies (Nguyet \& Mai, 2012).

Taken together, these researches are focusing on the communication strategies used including the effectiveness of CSs, the factors affecting CSs and the method used in teaching CSs. Relatively few studies have targeted the communication problems that can be solved by CSs. Among several communication strategies types as proposed by Tarone (1981) most of them are intended to solve the limitation of lexical items and grammatical problems. Most research on communication strategies has focused on lexical difficulties (Kasper \& Kellerman, 1997: 7). Also, it seems as though most recommended communication strategies can not be implemented in classroom instruction without the accompanying, relevant vocabulary (Dörnyei, 1995). Therefore, another value of CS instruction would be the extra benefit of vocabulary learning, specifically useful vocabulary that effectively furthers communication and learning. In order to know the balance of communication strategies 
used, it is important to know the most dominant communication problems solved. Therefore; the present study is focusing on lexical problems and grammatical problems with the assumption that lexical problems are most frequently coped by communication strategies. The study was guided by the following research questions: What are the lexical and grammatical communication problems that can be managed by Communication strategies?

\section{Communication Problems Managed by Communication Strategies in Tarone's Taxonomy}

The sociolinguistic oriented communication strategy is proposed by Tarone (1977). A communication strategy is categorized into sociolinguistic oriented when the two participants realize that they do not understand each other. Therefore this category view interactional aspect of communication strategy. This category emphasizes the cooperative interaction of the participants to keep the communication on. They should realize when the other participants need help to convey their communication gap. It focuses on how to help the learners encounter in the real communication by sharing their communication problem with the interlocutors.

Using the interactional approach, Tarone has defined communication strategy as a mutual attempt of two interlocutors to agree on a meaning in situations where requisite meaning structure. She works on the interlingual production specially to model the empirical observations of a study of second language learners' communication strategy. To clarify the definition, Tarone (1981: 288) proposes the criteria of communication strategies:

1. A speaker desires to communicate meaning $x$ to the listeners.

2. The speaker believes the linguistic or sociolinguistic structure desired to communicate meaning $\mathrm{x}$ is unavailable, or is not shared with the listener, thus the

3. The speaker chooses to:

a. Avoid: not attempt to communicate meaning

b. Attempt alternate means to communicate meaning $x$. the speaker stops trying alternatives when it seems clear to the speaker that there is shared meaning.

The communication problems sources explained by Tarone in all communication strategies are mostly on lexical problems and less on structural problems. According to Tarone (1981), there are avoidance, paraphrase, conscious strategy, appeal for assistance, and mime.

In using avoidance strategy, learner sometimes makes a deliberate decision not to speak because they expect communication problems to arise. This avoidance is a common strategy for second-language learners, causing them to remain silent when they would otherwise contribute to a conversation simply because some aspect of vocabulary or grammar is not known.

Tarone refines this avoidance strategy by distinguishing between topic avoidance and message abandonment. For topic avoidance, specific topic or words are avoided to the best of learner's ability. Learners manage to prevent the occurrence of topics that are certain to present difficulties. The learner simply tries not to talk about concepts for which the target language item or structure is not known. There are some utterances that substitute the unfamiliar nouns.

"Something that is on the wall and there is a tap with a..." (Garden house)

"You use it to make... if you eat"(Wooden Spoon)

(Tarone, 1981)

In message abandonment, learners hesitate into a topic that is too difficult and simply give up and go on to another. In this case, one might say that the learners should avoid the topic together since no real effort was made to conquer the problems. The learners begin to talk about a concept but are unable to continue and stop in mid-utterance.

Paraphrase strategy is the rewording of the message in an alternate, acceptable target language construction, in situation where the appropriate form of the situation is not known or not yet stable. This is a broad category and within it, Tarone (1981) identifies three types of paraphrase strategies. The first is approximation, which she defines as the use of single target language vocabulary item or structure, which the learner knows is not correct, which shares enough semantic features in common with the desired item to satisfy the learner. Approximation then includes virtually all word substitutions that the learner knowingly employs to serve in place of more accurate term. The substitute word can refer to the correct concept, but at an inappropriate level or refer to another object that may give some hint to the intended referent. In the following examples, learners tried to explain the unknown word by using the other familiar words. 
"You put a baby in it. It is like a hole."(playpen)

"It's look like the letter 'A'." (stool)

(Tarone, 1981)

The second strategy is word coinage; the learner makes up a new word in order to communicate a desired concept (Bialystok, 1990: 41). For example, when a learner creates airball to mean ballon clock, the strategy was to base the clock on the French word heure in general, clear cases of word coinage are less common than are instances of the other types of paraphrase strategies. Another example is "its spoon of wood" for 'wooden spoon'.

The final paraphrase strategy is circumlocution is a worldly extended process in which the learner describes the characteristics or elements of the object or action instead of using the appropriate target language structure. For example someone who wants to refer to some unknown words by explaining for features that may help the listener guess what intended object maybe (Tarone, 1981).

"She is, uh, smoking something, I don't know what's its name. That's, uh, Persian, and we use Turkey, a lot of." (waterpipe)

Conscious transfer strategy has some manifestations. The first is the literal translation of words or phrases, and the second in the interpersals of words from another language. The examples of literal translation are (Tarone, 1981):

"You can put animals or people in it and you pull it". (wagon)

"Something that you can sit in, it's very soft." (wing chair)

Language switch is the straight forward insertion of words from another language. Tarone (1977 in Byalstok, 1990: 45) changes this strategy into borrowing but kept the two subtypes of literal translation and language switch. An example is spoken by EFL learners when she switches the word in her L1 source such as (Tarone, 1981):

"You put a record on it." (record player)

"It's chair for a baby that you put in a car to keep you safe." (child's car seat).

An appeal for assistance has occurred when the learner has consulted any source of authority: a native speaker, the experimenter, a dictionary. The strategy is often smuggled onto other more verbal efforts, however, by such prosodic features as rising intonation which implicitly elicits some assistance or validation from the listener. In the following utterance, the learner asks for help to the interlocutor for the word "spatula" (Tarone, 1981).

Director: "You use it for cooking."

Learner: "What do you cook with it?"

Mime is the final strategy includes all nonverbal accompaniments to communication, particularly those that serve in the place of missing target-language word. Some concepts are easy to simulate, such as Tarone (1981) gives examples of the subject clapping his hands to indicate applause, but other gestures are considerably less interpretable by a listener.

\section{Previous Researches on Communication strategy}

Some researchers are focusing on lexical problems managed by communication strategies. Azar, et al. (2013) investigated the use of lexical and discourse based CSs by EFL teachers in Iran. The majority of EFL teachers used lexical-based CSs to compensate for lack of linguistic ability in their interlocutors. Analysis of items related to lexical based CSs revealed that, respondents mostly resorted to different kinds of achievement lexical-based CSs such as IL-based communication strategies to compensate breakdowns in the communication. According to obtained results by using the achievement or compensatory strategies, teachers tackled communication problems by an alternative plan for reaching their original goals. It seemed that EFL teachers used some other achievement lexical-based CSs, like use of fillers (to gain time to think), mime and gesture to help the effectiveness of teaching and fill the breakdowns in the communication. Compared to avoidance strategies, IL -based CSs are beneficial since they reflect the fact that learners make more positive attempts to tackle the difficulties they face in the process of communication. 
Halim, et al (2013) explored the oral strategies in the French beginners' foreign language class. From the three conversations, the study revealed that even though the learners were given a simple beginner task with learnt vocabularies (in this case, a self-presentation and introduction of friends), the learners still had the difficulties and sought a range of strategies to overcome their weakness in the French vocabulary. This is due to the fact that the dialogues were spontaneous, therefore, was limited in reforming the messages they wanted to convey as opposed to when they write. Literal translation from either English or Malay was the most dominant strategy, followed by all purposes words and message abandonment. Apart from limited vocabulary, these strategies were used extensively on the grammatical and structure rules in French. The usage of the strategy was equally due to the unlearned and forgotten vocabularies of the subjects, and approximation of the vocabularies to the English words. The reason was because the words in French and English have the same spelling, thus the learners assumed that its meaning should be the same without further checking. The results of this study were parallel to the study on the written communication by Halim et al. (2011) on the use of literal translation as the main strategy by French students. Parallel to the findings above, code switching was used by the learners for two reasons: they forgot certain vocabularies and switched to the language understood by all the audiences, and they tried to accommodate the French expressions which were not understood by the group members by switching to a language familiar to them. Finally, repetition strategy was used by the learners to overcome the uncertainties of what was being said by the group members, to gauge the group members' understanding of what was being discussed, to reassure him/herself of what was being discussed by the team members, and to compensate their lack of ideas to continue the conversation.

A study designed to examine the use of lexical and discourse-based communication strategies by Malaysian ESL learners to find out their inclination towards problem-solving and message enhancement (Ting, S.H. \& Lau, L.Y, 2008). Analysis of the strategies using a typology from Faérch and Kasper (1980; 1983; 1984), Tarone $(1980 ; 1981)$ and Clennell (1995) revealed some interesting patterns. It was found that instances of strategy use for message enhancement was half that of problem-solving. Gaps in communication were mostly bridged by frequent restructuring of utterances and there was minimal use of discourse based strategies, namely, comprehension checks and clarification requests. Instead two discourse strategies, tonicity and lexical repetition, were used with versatility for message enhancement, particularly by the more proficient learners. These findings are similar to previous studies by Ting (2005) and Ting and Phan (2008) that observed heavy reliance on restructuring in general and the greater use of discourse strategies by learners with higher proficiency in English.

Ismail, Rushita \& Kaur, (2012) found that regardless of the different levels of English proficiency, these learners share similar types of circumlocution strategy. This study demonstrates that the use of the types of circumlocution strategy to compensate for the linguistic knowledge among these two groups of learners (high intermediate and low intermediate level of English proficiency) is highly comparable. When there is a lexical difficulty and learners need to use a circumlocution CS, learners resort to three common types of circumlocution strategies for successful communication of the message. Moreover, learners, depending on their proficiency levels, may take quite an active role in making descriptions, references and citing examples in their oral communication. The finding of this study coincides with the earlier studies which revealed that the use of these strategies is the effective types and were used by the proficient level learners (Jourdain 2000; Liskin-Garparro 1996). High intermediate and low intermediate speaking interlocutors resort to the same types of circumlocution strategies but with different frequency. This seems to suggest that the proficiency level of the learner plays an important role on the learner's strategy choice. In the context established for the purposes of the present study, high intermediate level learners' interaction offer more opportunities for second language learning lexical input than low intermediate level learners' interaction.

Mei \& Nathalang (2010) suggested that students were likely to use different communication strategies for different types of tasks. Both a one-way task (concept identification) and a two-way task (role play) were used in this study to elicit the use of communication strategies from the participants. The one-way task performed with native speakers elicited more IL-based CSs from students such as paraphrase, restructuring and generalization, and avoidance strategies such as message abandonment. These CSs help students to get their meanings across and ensure listener comprehension. It is obvious that the two-way task required students to engage in more cooperative interactions in order to achieve their communicative goals. In this study, it was observed that, compared to LP Learners, HP learners used Inter Language based strategies more often and avoidance strategies less often. Compared to avoidance strategies, inter Language-based CSs are more beneficial since they involve more positive attempts to actively tackle the difficulties students face during the communication process, instead of avoidance. Teachers may believe that once students are willing to deal with the difficulties they have with language production, gradual improvement can be expected. This is likely due to the fact that LP students have less confidence in using the English language. Hence, they sometimes mime or switch to L1 (Chinese) when communicating in English. After students have studied English for six or more years, and their grammatical competence has developed, their strategic competence should be monitored. 
Improvements in learners' strategic competence (a major component of communicative competence) can contribute to the development of their communicative competence.

In general the studies showed that most of communication used in order to improve learners interlanguage. The problems investigated are lexical and grammatical. The finding also shows that once students are willing to deal with the difficulties they have with language production, gradual improvement can be expected.

\section{Research Method}

\section{Participants}

Participants of the study are four years of EFL learners in East Java Indonesia. The learners are randomly selected from one class for each year. The learner's number is 60 learners. It is expected that from such number of subjects, the result of the research is more wide-ranging. The level of proficiency of the participants is mixed.

\section{Material}

There are three instruments needed in collecting the data. One of the instruments needed in elicitation is printed narrative picture. It consists of sixteen pictures that are put separated. Though, the pictures have been arranged in the good orders. Another instrument is observation guidance which is needed in doing the observation. The observation guidance is in the form of communication strategy table which consists of appeal for assistance strategy and mime. Those two strategies cannot be caught using neither sound recording nor video recording; therefore a close observation is needed.

\section{Data Collection Procedure}

Elicitation technique refers to the manner in which the language is elicited from the subject of the study. The elicitation technique is used to collect the data in the form of speech samples. A natural communication task is needed in the elicitation. Therefore there is an elicitation tasks used, namely narrative picture.

The narrative cartoon is titled "Piggy Bank Thieves". This narrative picture is unfinished yet. It represents sixteen scripts and two blank texts to finish the narrative. In this elicitation, learners should produce oral narrative based on the picture presented. Besides, they should finish the narrative by their own creation. This technique is particularly useful to create processing problem for the learners. This narrative picture seems to offer some difficulties. Since there is no verbal information such as the title of story, keywords relating to the meaning, utterances of the characters involved, the verbalized task is not prompted. An observation technique is a data collection technique performed during the elicitation. An observation is a data collection technique which needs interview guidance to note the non-verbal strategy such as mime. This strategy is viewed through complete observation without participating. In doing the observation, the researcher does not directly involved in the elicitation with the subjects.

This technique is important to retrieve the data from the learners' memory which cannot be perceived by sound nor video recording. Therefore, this technique is appropriate to take a note of any information outside the spoken language or non-verbal language.

Any Information revealed during the observation is also recorded using audiovisual materials such as sound recording and video recording. These tools provide opportunities for the subjects to share their reality. Therefore they are effective tools in captures subjects' real performance. Only the real performance can show the non-verbal language of the subjects.

\section{Data Analysis}

Preparing the data for analysis is the primary step. This step involves transcribing the utterance produce by the learners during the elicitation. Then, typing up the field notes as the outcome of the observation and arranging the data into different types depending on the sources of information. The data is organized categorically and chronologically. 
The next step is reading through all the data in order to obtain general sense of the information to reflect on its overall meaning. The information can be the general ideas that the subjects are saying. After that, the general thoughts leads to identify the communication strategies employed.

Detailed analysis by the classification process is the next step. Classification is the process of organizing the material into chunks before bringing the meaning to those chunks. In involves taking text data into categories and labelling those categories with communication strategy types using communication strategy classification card. This classification is gleaned from communication strategy typology proposed by Elaine Tarone (1981). The data are confirmed with the past information or diverged from the theory.

\section{Result and Discussion}

The oral communication strategies employed by the students were classified into five: The first is avoidance (topic avoidance and message abandonment), paraphrase (approximation and word coinage and circumlocution), and conscious transfer (literal translation and language switch), appealing for assistance and miming. The study shows that the percentages of lexical problems managed by communication strategy are higher than grammatical problems. It can be seen from table 1.

Table 1 Frequency of lexical problems and grammatical problems managed by communication strategies.

\begin{tabular}{rlll}
\hline No & Types of CSs & Lexical problems & Grammatical problems \\
\hline A & Avoidance Strategy & & \\
1. & Topic avoidance & & $0.9 \%$ \\
2. & Message abandonment & $0.9 \%$ & \\
B & Paraphrase & & \\
$\mathbf{1}$ & Approximation & $20 \%$ & $26 \%$ \\
$\mathbf{2}$ & Word coinage & $9.6 \%$ & \\
$\mathbf{3}$ & Circumlocution & $5.7 \%$ & $0.9 \%$ \\
C & Literal translation & $24 \%$ & \\
D & Appeal for assistance & $9.6 \%$ & \\
E & Mime & $1.9 \%$ & $\mathbf{2 7 . 8} \%$ \\
Total & & $\mathbf{7 2 \%}$ & \\
\hline
\end{tabular}

\section{Lexical problems managed by communication strategies}

Message abandonment

In message abandonment, learners hesitate into a topic that is too difficult and simply give up and go on to another. In this case, one might say that the learners should avoid the topic together since no real effort was made to conquer the problem. The learners begin to talk about a concept but are unable to continue and stop in mid-utterance. This strategy is included in the following utterance.

"When he arrive at home he found the robber is ... and then the robber..two robbers..he saw two thieves that want to steal piggy bank".

The learner begins to talk about a concept but is unable to continue and stops in the middle of her utterance. She avoids using the unknown word. She tries to talk about the robbers who want to steal the piggy bank but she cannot continue. Afterward, she plans to produce the more appropriate sentence structure, and she can do it after all. Firstly, she speak "when he arrive at home, he found the robber is..." In the utterance, she may want to continue her utterance to be "when he arrives at home, he found the robber open the wardrobe". She prefers to switch to other concept that is represented by the next picture. She avoids talking about the word "wardrobe". 
Paraphrase

Tarone (1981) defines paraphrase as the rewording of the message in an alternate, acceptable target language construction, in situation where the appropriate form of the situation is not known or not yet stable. This is a broad category and within it, Tarone identifies three types of paraphrase strategies that are approximation, word coinage, and circumlocution.

Approximation

Approximation is the use of single target language vocabulary item or structure, which the learner knows is not correct, which shares enough semantic features in common with the desired item to satisfy the learner. Approximation then includes virtually all word substitutions that the learner knowingly employs to serve in place of more accurate term. The substitute word can refer to the correct concept, but at an inappropriate level or refer to another object that may give some hint to the intended referent. These strategies are presented in the following utterances.

"Then, the thieves got into the cupboard...yes.., Billy locked the cupboard after that Billy called the police".

In this approximation strategy learner replaces the word "wardrobe" with "cupboard". He has difficulty with the lexical item for a tall cupboard for hanging clothes or "wardrobe". He thinks that cupboard is the general word for any object to keep dresses, dishes and provisions. Actually cupboard is only small furniture with doors that is usually used to keep dishes in the kitchen. This word is actually inappropriate but he has tried to make the listener understand.

Word Coinage

The second type of paraphrase strategy is word coinage. The learner makes up a new word in order to communicate a desired concept (Tarone, 1981).

"I went from my house with my dog"

The phrase "I went from" is a form of word coinage strategy. In this phrase, she substitutes the more appropriate word "left". She may consider the word "went from" is the antonym of "went to" so she prefers this word to be chosen. She tries to create new word that is unknown in the English words.

"They are opening the wardrobe and look saving money box"

The learner uses word coinage strategy. She faces the problem of difficult vocabulary. She does not know the right word for a container that shape like a pig or "piggy bank". Therefore she creates a new word that represents the word she refers to. The phrase "saving money box" means box for saving money. Though this word is not appropriate, but it shares enough meaning.

Circumlocution

The final paraphrase strategy is circumlocution is a wordly extended process in which the learner describes the characteristics or elements of the object or action instead of using the appropriate target language structure. For example someone who wants to refer to some unknown words by explaining for features that may help the listener guess what intended object maybe.

"They open a cupboard and try take a pig... something like a pig".

"They enter other house and open a box with something in it like a money...I think".

The learner used circumlocution strategy. She has a problem with a lexical item. Therefore, she describes the characteristics of the object she does not know exactly. She uses the phrase "something like a pig" for describing "piggy bank". It is considers as strategy because by circumlocution, she can continue to speak though the object is not obviously described. The other circumlocution strategy is also found. The learner tries to describe the character of the object. She uses the phrase "a box with something in it, money I think" to refers a "safety deposit box". Using this strategy he can keep speaking.

Conscious Transfer: Literal Translation 
Conscious transfer has some manifestations. The first is the literal translation of words or phrases. The learner translates word for word from the L1 language. It is presented in the following utterance.

"He took car in the.. in beside Rony home"

The learner translates Indonesian structure into English sentence. She may unfamiliar with the rule of preposition "in" and "beside". Consequently, she combines the preposition "in" and "beside". In this way, she transfers her Indonesian structure "di samping" into English structure "in beside". She does not know that " $d i$ samping" in Indonesian is translated to be "beside". The correct form should be "beside Rony's Home".

Language switch

Language switch is the straight forward insertion of words from another language. Tarone (1981) changes this strategy into borrowing but kept the two subtypes of literal translation and language switch. The learners use eight strategies. They are presented in the following utterances.

"They stool much money from the brankas"

The learner uses language switching strategy when feel difficult to find the correct word. The word "brankas" for replacing the word "safety deposit box". It is a strong box for keeping money or valuable thing. "brankas" is the common word used by Indonesian people to name such box. He may think that the listener can catch the meaning though he does not know what language is the word "brankas" taken from.

Appeal for Assistance

An appeal for assistance has occurred when the learner has consulted any source of authority: a native speaker, the experimenter, a dictionary. The strategy is often smuggled onto other more verbal efforts, however, by such prosodic features as rising intonation which implicitly elicits some assistance or validation from the listener. They can be seen in the following utterances.

“They open the cupboard and took something I don't...know...(piggy bank) oh ya piggy bank”.

In this utterance learner uses the appeal for assistance. She has a problem of difficult word. Therefore, she uses the phrase "I don't know" for asking help to the listener. Though she does not say directly, but her signal shows that she needs to be helped to find the word for "piggy bank". This strategy is effective to solve her problem.

Mime

This final strategy includes all nonverbal accompaniments to communication, particularly those that serve in the place of missing target-language word. Some concepts are easy to simulate, such as Tarone (1981) gives an example of the subject clapping his hands to indicate applause, but other gestures are considerably less interpretable by a listener. The first year learner only uses one strategy. It presented in the following utterances.

"The dog is success to ...(move her hand to push something) the robbers into the cupboard".

The learner uses a gesture to express her meaning. She wants to say t wardrobe" but she does not know the word "lead". Therefore she tries to make the listener understand using the gesture " pushing her hand forward" that means "lead".

\section{Grammatical problems managed by communication strategies}

Topic avoidance

For topic avoidance, specific topic or words are avoided to the best of learner's ability. Learners manage to prevent the occurrence of topics that are certain to present difficulties. The learner simply tries not to talk about concepts for which the target language item or structure is not known. The problems of lexical item can be solved in the managed in the in the following utterance.

"After that they look at the piggy bank and the boy ...there is a dog attack the two men".

The problems found in the utterance is failure of forming grammatical sentence. The learner stops talking and prefer to change the concept. She wants to say that the boy commands his dog to bark the robbers, 
but she feels difficult to start from the "boy", therefore she stops from "the boy..." and change to the other concept by restructuring new sentence "there is a dog attacks the two men". By stop talking, she has enough time to plan the other concept that can replace the difficult one. This strategy can help her keep the communication on.

\section{Approximation strategy}

In these strategies, learners try to substitute structure that can refer to the correct concept, but at an inappropriate level that may give some hints to the intended referent. These strategies are presented in the following utterances.

"After took it, Billy's dog attacked them and the dog barked the thieves".

"After took a walk he went to his house there were two thieves, one thief was fat and one was thin".

"After took it, Billy's dog attacked them".

"When I came back from take a walk I want to get into my house".

In the approximation strategy learners use incorrect verb form but it does not change the meaning of the whole utterance. The learner has made an error by using the past tense "took" after the preposition "after". In the correct form, he should use the verb-ing after the preposition "after". Therefore, the correct form should be "after taking". In this way, the learner over generalizes the past verb "took" for any context of time and does not ignore the exception of using the past verb. The problems of verb form are repeated for many times because the learners do not use different verbs after conjunction in Indonesian for example the Indonesian conjunction setelah (after) is followed by mengambil (take). The word mengambil remains the same even though there is no preceding preposition we can see in the phrase Setelah mengambil (after taking) or mengambil buku (take book).

Consequently, learners do not aware of changing the verbs. We can see these on the sentences "Billy and his dog took a walk and Billy was on his bike and his dog ran behind him". These errors are considered as kind of strategies to compensate communication problem and it is not slip of the tongue because he repeated these errors for many times such as in "After took a walk he went to his house there were two thieves, one thief was fat and one was thin" and "after took it, Billy's dog attacked them". Another approximation strategy can be seen in using inappropriate verb "from take". She uses the verb "take" for replacing the verb -ing "taking. She has broken the English rule of using verb -ing after preposition. The appropriate form should be "from taking".

"When I was took a walk with my dog, I was very happy".

In the utterance, learner uses the past -be form "was" before the verb "take". He breaks the rule of English structure that "was" must be followed by adjective or adverb. He should say "I took". The problem of using be is also common in Indonesian since it does not have "be" form. Using "was or be" in this strategy, he tries to make the listener understand. Though she has made error but the meaning can be shared.

\section{Literal Translation}

Conscious transfer has some manifestations. The first is the literal translation of words or phrases. The learner translates word for word from the L1 language.

"The robbers come to inside the wardrobe because they scared with the dog".

The learner used this strategy by translating her first language structure into the English utterance. As a result, she ignored the correct term in English. She translated the word "to" to be "ke" in Indonesian. Then he adds the word "inside" to refers "dalam" in Indonesian. After that, he combined those words to be "to inside" that means "ke dalam" in Indonesian. This phrase is used to replace the phrase "come into".

\section{Conclusion}

The main purpose of this study was to investigate the lexical and grammatical problems managed by communication strategies used by EFL learners in Indonesian in context. Concerning the results of the study, it was revealed that there was a significant difference in the frequency and percentage of learners' solved lexical problems $(72.2 \%)$ and grammatical problems $(27.8 \%)$. The data confirming or rejecting this hypothesis were collected through an elicitation task done by EFL learners. The results drawn from these items were that EFL learners used communication strategies on lexical problems are more frequent than used communication strategies on grammatical problems. 
This strategy is one small step towards clarifying the balanced of using communication strategy on lexical and grammatical problems in communication. The communication strategies applied by the learners should be matched with the teaching goal. If the teaching focuses on grammatical correctness, so the teaching method should foster the avoidance and approximation strategy. Whereas, if the teaching goal concerns on lexical items, the teaching method should promote the conscious transfer strategy, appeal for assistance and mime. The appropriate strategies selection will help the learner achieves the learning goal.

The result of this study will help to stimulate the learner to be more aware of the positive advantages that the communication strategies offer. They could learn from the study of their own strategic competence. The teaching of communication strategy can be useful for supplement that involves attention on different aspect of communicative competence.

Finally this study will stimulate to other research that yield on communication strategy. The further research can concern on how to teach and develop communication strategy for coping wider communication problems. Researches on communication strategies has witnessed great achievements, however, these are concentrated almost exclusively on lexical problems. There is still the lack of investigation on issues like, the learners solve grammatical, pragmatic problems other than lexical ones by using communication strategies and the existing research results cannot solve the grammatical problems.

\section{References}

Azar, Ali Sorayyaei, \& Mohammadzadeh, Reza. (2013). The Investigation of Lexical and Discourse-based Communication Strategies Used by EFL Teachers in the Classrooms. Journal of Educational and Social Research Vol. 3 (2) pp.317-334.

Bachman, Lyle F. (1990). Fundamental Considerations in Language Testing. Oxford: Oxford University Press.

Brown, H.D. (1987). Principles of Language Learning and Teaching. Englewood Cliffs: Prentice-Hall. Inc.

Canagarajah, Syresh.(2007). Lingua Franca English, Multilingual Communities, and Language Acquisition. The Modern Language Journal, 91, Focus Issue, (2007) pp. 923-939

Clennell, C. (1995). Communication strategies of adult ESL learners: A discourse perspective, Prospect, 10 (3), 4-20.

Dong, Yang, \& Peng, Gai Fang. (2010). Chinese Learners' Communication Strategies. Cross-Cultural Communication. Vol. 6, No. 1, 2010, pp. 56-81. www.cscanada.net.

Dornyei, Z. (1995). On the teachability of communication strategies. TESOL Quarterly, Vol. 29/1, pp.55-85.

Ellis. R. (1985). Understanding Second Language Acquisition. Oxford: Oxford University Press.

Ellis.R. (2004). Analysing Learner Language. Oxford : Oxford University Press

Ismail,Rushita, \& Kaur,Sarjit. (2012). Teacher Collaboration: Shaping the Classroom of the Future. ThaiTESOL. Pp. 1-16.

Kasper. G. and E. Kellerman. (1997). Communication Strategies: Psycholinguistic and Sociolinguistic Perspectives. London: Longman.

Kellerman, E. (1991). Compensatory strategies in second language research: A critique, a revision, and some (non-)implications for the classroom. In R. Phillipson, E. Kellerman, L. Selinker, M. Sharwood Smith, \& M. Swain (Eds.), Foreign/second language pedagogy research (pp. 142-161). Clevedon, UK: Multilingual Matters.

Mei,An \& Nathalang . (2010). Use of Communication Strategies by Chinese EFL Learners. Chinese Journal of Applied Linguistics (Bimonthly) Vol. 33 No. 3,pp.110-125.

Nguyet, Nguyen Thi Minh \& Mai, Le Thi Thuyet, (2012). The Use of Circumlocution Communication Strategies in ESL Dyadic Interaction. Language Education in Asia, 3(1), 32-49. http://dx.doi.org/10.5746/LEiA/12/V3/I1/A04/ 
Selinker, L (1972). Interlanguage. International review of applied linguistics, 10, 209-230

Ting, S.H. \& Lau, L.Y. (2008). Lexical And Discourse-Based Communication Strategies Of Malaysian ESL Learners, Malaysian Journal Of ELT Research, Vol. 4, pp.18-31. www.melta.org.my.

Tarone, Elaine. (1977). Conscious communication strategies in interlanguage. In H. D. Brown, C. A. Yorio, and R. C. Crymes (eds), ON TESOL '77. Washington, D. C. TESOL.

Tarone, E. (1980). Communication strategies, foreigner talk and repair in interlanguage. Language Learning, 30, 417-431.

Tarone, E. (1981). Some thoughts on the notion of communication strategy. TESOL Quarterly, 15, 285-295. 